\title{
The Effect of Concurrent Radiochemotherapy on Pulmonary Function Tests: Can Radiation Pneumonitis be Predicted?
}

\author{
(D) Esra KORKMAZ KIRAKLI,' () Ufuk YILMAZ²
}

'Department of Radiation Oncology, Dr. Suat Seren Chest Diseases and Surgery Training and Research Hospital, Izmir-Turkey ${ }^{2}$ Department of Chest Diseases, Dr. Suat Seren Chest Diseases and Surgery Training and Research Hospital, İzmir-Turkey

\begin{abstract}
OBJECTIVE
The aim of the present study was to evaluate the extent of change in pulmonary function tests (PFTs) in early and late term after concurrent radiochemotherapy (RCT) and whether the baseline PFTs or percentages of changes in PFTs after RCT would predict radiation pneumonitis (RP) after RCT in locally advanced non-small cell lung cancer (NSCLC).

METHODS

Patients with stage III NSCLC who received RCT between January 2008 and December 2014 were evaluated retrospectively with respect to patients, tumor, and treatment characteristics; PFT parameters before RCT; 1, 6, and 12 months after RCT; response rates; progression-free survival (PFS); and 5-year overall survival (OS). PFT parameters at 1, 6, and 12 months after RCT were compared with the same patients' baseline values. RP was assessed both clinically and radiologically.
\end{abstract}

\section{RESULTS}

A total of 61 patients were analyzed in the study. Median follow-up was 20 (4-116) months, and PFS was 14 (2-122) months. Five-year OS was 18\%. All PFT parameters declined after RCT, but only decreases in forced expiratory volume in 1 second at 6 and 12 months and in diffusion capacity of the lung for carbon monoxide (DLCO) at 6 months were found to be statistically significant. None of the baseline PFT parameters was found to be predictive of RP except the baseline DLCO; patients who had a baseline DLCO value $<65 \%$ $(52 \%-75 \%)$ developed RP in contrast to patients who had baseline DLCO value $>75 \%(71 \%-95 \%)(p=0.023)$.

\section{CONCLUSION}

There has been prominent and persistent decrease in PFT after RCT. However, the clinical outcome of this finding has to be evaluated. Further prospective studies with larger scales are needed to verify the predictive value of baseline DLCO on the development of RP.

Keywords: Non-small cell lung cancer; pulmonary function tests; radiochemotherapy. Copyright $\odot$ 2019, Turkish Society for Radiation Oncology

\section{Introduction}

Concurrent radiochemotherapy (RCT) is the standard treatment for locally advanced non-small cell lung cancer (LA-NSCLC).[1] However, radiation-induced lung damage is multifactorial and inevitable and limits dose resulting in decreased treatment success. [2] Pulmonary function tests (PFTs) are the objective methods to measure the lung function. $[3,4]$

Radiation pneumonitis (RP) is the major radiation-induced toxicity after thoracic radiotherapy (RT), and there has been no algorithm for radiation

This study was presented as an oral presentation in VIII ${ }^{\text {th }}$ National Lung Cancer Congress at $7^{\text {th }}$ October 2018.

Received: March 18, 2019

Accepted: April 14, 2019

Online: May 28, 2019

Accessible online at:

www.onkder.org

OPEN ACCESS This work is licensed under a Creative Commons

Attribution-NonCommercial 4.0 International License.
Dr. Esra KORKMAZ KIRAKLI

Dr. Suat Seren Göğüs Hastalıkları Cerrrahisi,

Eğitim ve Araştırma Hastanesi,

Radyasyon Onkolojisi,

İzmir-Turkey

E-mail: esrakirakli@gmail.com 
oncologists to predict RP before RT with today's clinical practice.[5]

The primary aim of the present study was to evaluate the extent of change in PFTs in early and late term after concurrent RCT and whether baseline PFTs and percentage of changes in PFTs after RCT would predict RP after RCT in LA-NSCLC. The secondary aim was to investigate if baseline forced expiratory volume in 1 second (FEV1) could be a prognostic factor for survival.

\section{Materials and Methods}

\section{Study Design}

Patients with stage III NSCLC who received concurrent RCT between January 2008 and December 2014 were enrolled in this retrospective cohort study. Patients' data derived from hospital records were evaluated with respect to patient characteristics, Eastern Cooperative Oncology Group (ECOG) performance status, weight loss, histological subtype, tumor stage (according to the TNM $7^{\text {th }}$ edition), treatment characteristics, and PFT values (percentage of predicted) before RCT (baseline) and at 1,6 , and 12 months after RCT. PFT parameters at 1, 6, and 12 months after RCT were compared with the same patients' baseline values.

PFTs included percentage of predicted FEV1\%, forced vital capacity (FVC), vital capacity, and diffusion capacity of the lung for carbon monoxide (DLCO). We select percentages instead of absolute values to minimize the confounding effects of age, gender, and height.

In patients who had more than one PFT before RCT, the one closest to RCT initiation was used for analysis. Treatment outcomes, response rates, progression-free survival (PFS), overall survival (OS), and 5 -year survival were reviewed. PFS was calculated from the last day of RCT until locoregional relapse or distant metastasis occurred. OS was measured from the date of diagnosis to the date of death. OS data were collected from the national database.

\section{RT Planning}

The patients were treated mostly with three-dimensional conformal RT (3D-CRT) and intensity-modulated RT. RT was delivered using conventional fractionation ( $1.8 \mathrm{~Gy} /$ day, 5 days/week) with a total dose of 60-63 Gy using 6/18 MV photon beams. Involved field technique was used for RT planning. The gross tumor volume (GTV) consisted of the primary tumor and the regional lymph nodes considered positive (SUVmax $>2.5$ ) on positron emission tomography (PET) scan even if not involved by computed tomography (CT) scan. Any intrathoracic lymph nodes with a diameter $>10 \mathrm{~mm}$ in the short axis were included in GTV regardless of the PET scan. For GTV definition on CT, pulmonary window settings were used to contour the pulmonary tumor and hilum, and the predefined mediastinal window settings were used to contour the mediastinal lesions. Margins for GTV to clinical target volume (CTV) were $6 \mathrm{~mm}$ for squamous cell carcinoma and 6-8 $\mathrm{mm}$ for other histologies. To generate the planning target volume (PTV), 5-10 $\mathrm{mm}$ margin was added to the CTV to compensate set-up errors and target motion. After 45-46 Gy, RT was delivered to a boosts volume encompassing the primary tumor and lymph nodes known to be involved with disease. The corrections for tissue inhomogeneities were applied. QUANTEC normal tissue dose constraints were administered.

Dosimetric factors, mean lung dose (MLD), and percentage of normal lung volume that receive $20 \mathrm{~Gy}$ (V20) were assessed from dose volume histograms.

\section{Chemotherapy}

Concurrent CT scheme was cisplatin $50 \mathrm{mg} / \mathrm{m}^{2}$ on days $1,8,29$, and 36 and etoposide $50 \mathrm{mg} / \mathrm{m}^{2}$ on days 1-5 and 29-33. The consolidation CT was never used.

PFT values after RCT at 1,6 , and 12 months were compared with the same patients' baseline PFT values.

\section{Toxicity Grading}

Pulmonary toxicity was graded according to the Radiation Therapy Oncology Group/European Organization for Research and Treatment of Cancer acute and late radiation morbidity scoring system. [6] RP was assessed in each case one by one through the evaluation of medical records and radiological findings retrospectively by a radiation oncologist and a chest physician who are dedicated on the treatment of lung cancer. RP was defined as $\geq$ grade 1 lung morbidity, whereas clinically important RP was defined as $\geq$ grade 2 lung morbidity.

\section{Statistical Analysis}

All survival analysis was performed using the KaplanMeier method. Continuous variables were expressed as mean \pm standard deviation or median (min-max) where available. To assess the differences between PFTs at 1,6 , and 12 months relative to baseline, repeated measures ANOVA test was used. The relationship between the clinical (age, gender, weight loss, location of tumor, and PTV) and dosimetric variables (MLD and V20) that are considered to be related with the decline 
in PFT values or RP risk was tested in univariate analysis. Since all patients had stage III, ECOG 0-1, received the same concurrent CT scheme, and treated with the same fractionation and mostly $3 \mathrm{D}-\mathrm{CRT}$, these factors were not included in the univariate analysis. p-values were derived from two-tailed tests. A p-value $<0.05$ was considered as statistically significant.

\section{Results}

A total of 61 patients who had baseline and follow-up PFTs were analyzed in the study. The median age of the patients was 58 (42-73) years. The patient characteristics are shown in Table 1. Median follow-up was 20 (4$116)$ months, and PFS was $14(2-122)$ months. Median OS was 20 (4-122) months. Five-year OS was $18 \%$.
The mean baseline PFT values are shown in Table 2. The percentages of changes in PFTs at 1, 6, and 12 months after RCT are shown in Figure 1. All values declined after RCT, but only decreases in FEV 1 at 6 and 12 months and DLCO at 6 months after RCT were found to be statistically significant. There was a decrease in all PFT values 1 month after RCT that was more pronounced at 6 months. At 12 months, only DLCO showed a 4\% increase, and all other parameters showed further decreases.

In univariate analysis, none of the clinical characteristics or dosimetric factors of the patients was found to be associated with the decline in PFT values or RP risk. Univariate analysis of clinical and dosimetric variables that are considered to be related with the decline in PFT values and RP risk are represented in Tables 3 and 4 , respectively. a
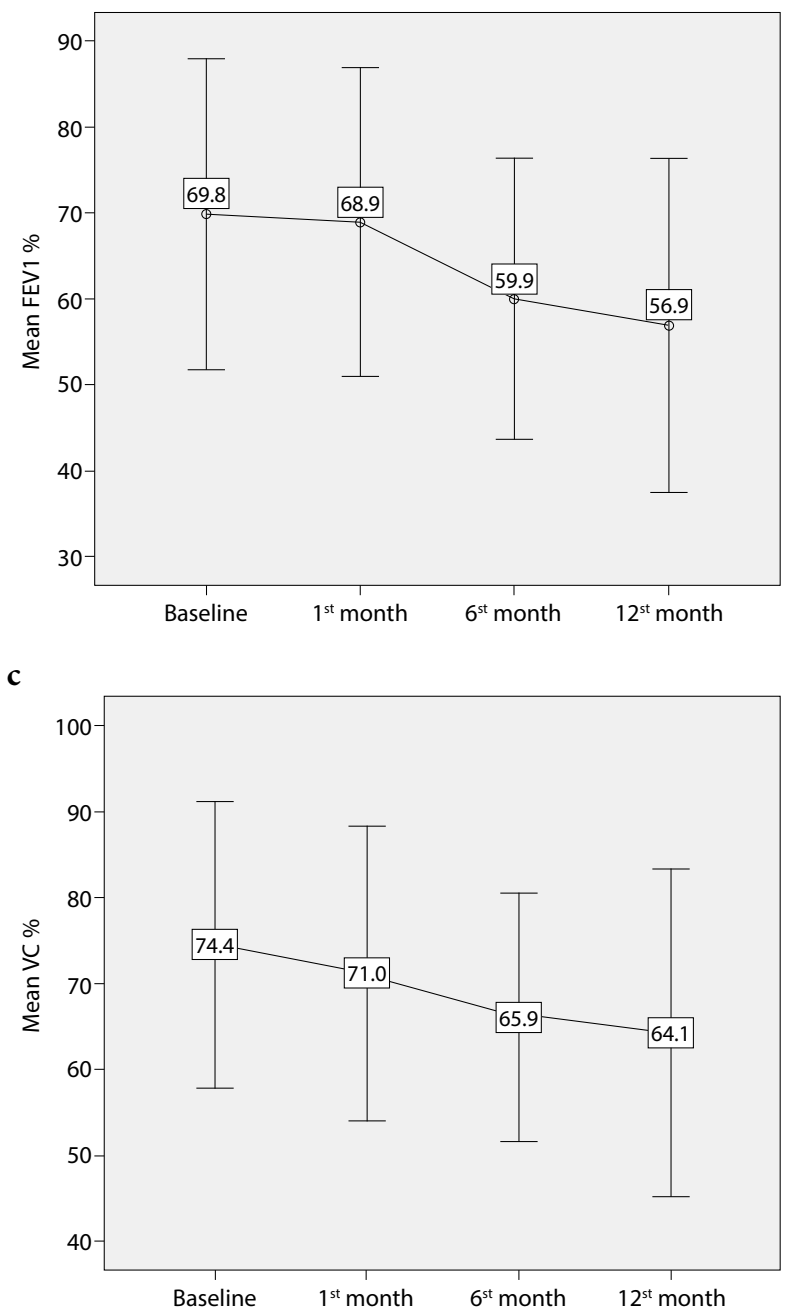

b

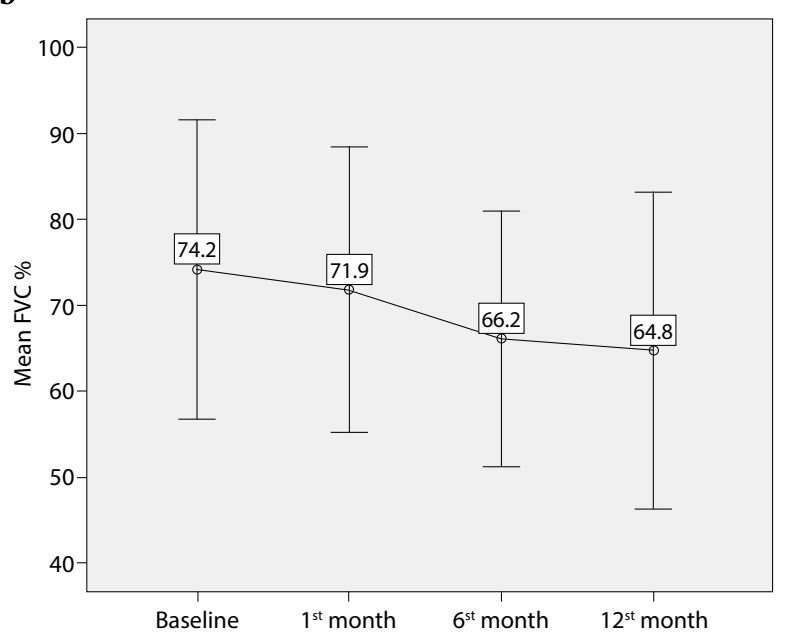

d

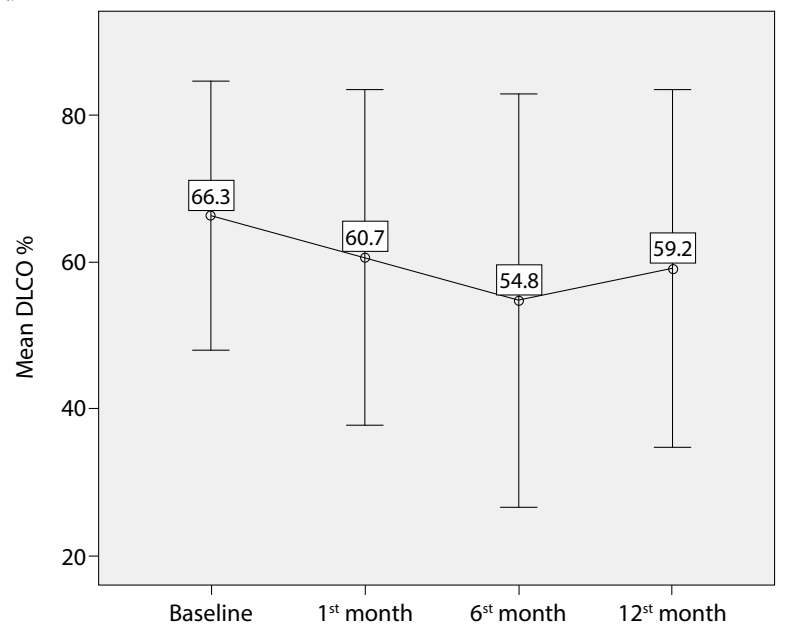

Fig. 1. The graphics of change in pulmonary function test values in time. (a) FEV1 \%, (b) FVC \%, (c) VC \%, (d) DLCO \%. 
Table 1 Patient, tumor and treatment characteristics

\begin{tabular}{|c|c|}
\hline Characteristics & n (\%) \\
\hline \multicolumn{2}{|l|}{ Gender } \\
\hline Female & $5(8)$ \\
\hline Male & $56(92)$ \\
\hline \multicolumn{2}{|l|}{ Histology } \\
\hline Squamous & $47(77)$ \\
\hline Adenocarcinoma & $11(18)$ \\
\hline NSCLC & $3(5)$ \\
\hline \multicolumn{2}{|l|}{ Stage } \\
\hline Illa & $27(44)$ \\
\hline IIllb & $34(56)$ \\
\hline \multicolumn{2}{|l|}{ Location of tumor } \\
\hline Upper lobe & $37(61)$ \\
\hline Middle or lower lobe & $24(39)$ \\
\hline \multicolumn{2}{|l|}{ ECOG } \\
\hline 0 & $37(61)$ \\
\hline 1 & $24(39)$ \\
\hline \multicolumn{2}{|l|}{ Weight loss } \\
\hline None & $40(66)$ \\
\hline$<5 \%$ in the last 6 months & $11(18)$ \\
\hline $5 \%-10 \%$ in the last 6 months & $5(8)$ \\
\hline Unknown & $5(8)$ \\
\hline \multicolumn{2}{|l|}{ RT technique } \\
\hline 3D-CRT & $58(95)$ \\
\hline IMRT & $3(5)$ \\
\hline Median RT dose $\left(25^{\text {th }}-75^{\text {th }}\right.$ percentile) & 63 Gy (63-63) \\
\hline Median PTV (min-max) & $639(302-1215)$ \\
\hline Median MLD (min-max) & $13(6-21)$ \\
\hline Median V20 (min-max) & $24.5(3.7-35)$ \\
\hline \multicolumn{2}{|l|}{ Radiological response rates } \\
\hline Stable & $8(13)$ \\
\hline Partial & $28(45)$ \\
\hline Complete & $20(34)$ \\
\hline Progressive & $5(8)$ \\
\hline
\end{tabular}

Table 2 The mean baseline pulmonary function test values

\begin{tabular}{ll} 
PFT & $\% \pm$ SD \\
\hline FEV1 & $69.8 \pm 18$ \\
FVC & $74.2 \pm 17$ \\
VC & $75.5 \pm 16$ \\
DLCO & $66.3 \pm 18$ \\
\hline
\end{tabular}

The incidences of grade $0,1,2,3$, and 5 pneumonitis were $14(23 \%)$ patients, $20(33 \%)$ patients, $22(36 \%)$ patients, $4(7 \%)$ patients, and $1(1 \%)$ patient, respectively.

None of the baseline PFT values was found to be predictive of RP except the baseline DLCO; patients who had a baseline DLCO value $<65 \%(52 \%-64 \%)$ de-

\begin{tabular}{lccc} 
Table 3 & \multicolumn{3}{c}{$\begin{array}{l}\text { Univariate analysis of clinical and dosimetric } \\
\text { variables that are considered to be related with } \\
\text { decline in PFT values }\end{array}$} \\
Variable & $\boldsymbol{\beta}$ & $\mathbf{p}$ & $\mathbf{C l}$ \\
\hline Age & 0 & 0.95 & $-0.01-0.01$ \\
Gender & -0.07 & 0.57 & $-0.33-0.19$ \\
Tumor location & 0.02 & 0.86 & $-0.24-0.28$ \\
Weigt loss & 0.01 & 0.82 & $-0.08-0.11$ \\
PTV & 0 & 0.41 & $-0.01-0.01$ \\
MLD & -0.04 & 0.77 & $-0.03-0.02$ \\
V $_{20}$ & 0.01 & 0.24 & $-0.06-0.23$ \\
\hline
\end{tabular}

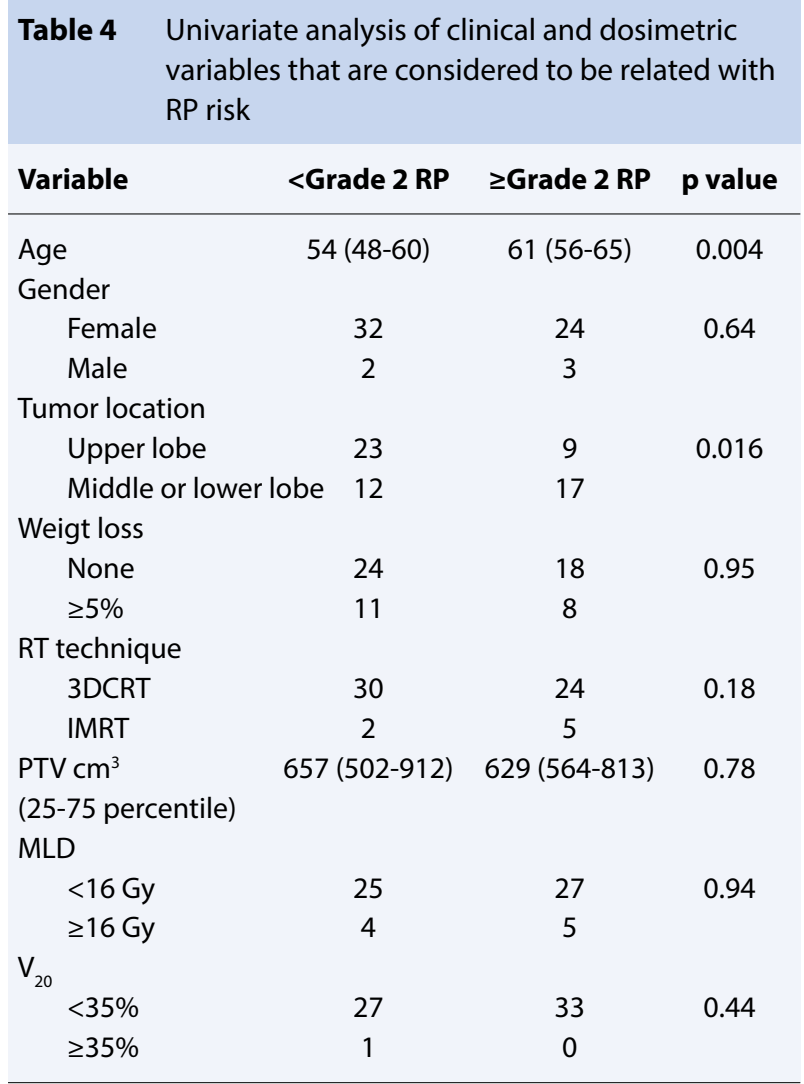

veloped RP in contrast to patients who had a baseline DLCO value $>75 \%(76 \%-95 \%)(\mathrm{p}=0.023)$. When the $\mathrm{RP}$ criteria were changed as clinically important RP $(\geq$ grade 2), DLCO was not associated with RP development. There was no any correlation between the percentages of changes in PFT values and development of RP. There was no any correlation between clinical and dosimetric factors and development of RP.

When we repeated the analysis by excluding the 5 patients relapsing in the thorax to avoid the effect of recurrent tumor or current therapies on PFT parame- 
ters, the results did not change. Baseline FEV1 was not found to be a prognostic factor for survival.

\section{Discussion}

In our study, patients with LA-NSCLC showed a persistent decrease in all PFT values compared with baseline, starting at 1 month after RCT that became prominent at 6 months and continued to decrease at 12 months. None of them recovered to baseline values. DLCO at 6 months and FEV 1 at 6 and 12 months were the parameters that showed the statistically significant decreases. Nevertheless, we could not find any correlation between the rate of decreases and the prediction of RP.

We observed that FEV1 and DLCO values did not recover and decreased to almost $20 \%$ of their baseline 1 year after RCT. Similarly, Borst et al.[7] reported that their cohort also shows no recovery in any parameter at 18 and 36 months after RT. Torre-Bouscoulet et al.[5] reported that none of the PFT values returns to their baseline values after RCT, and that decreases in PFT values are not associated with the development of $\mathrm{RP}$, which are very similar findings with our study.

In addition, the re-evaluation of the results by excluding the relapsing patients in the thorax enabled us to eliminate the confounding effects of the recurrent tumor and salvage therapies on PFT that might have clarified the effect of RCT on PFT.

In the literature, it has been stated that the largest change in PFT occurs in DLCO after RT and may predict RP. $[3,8-10]$ This finding might be explained by the concept that perfusion might be affected more than ventilation with RT. Similarly, in our study, among baseline PFT values, only DLCO was found to be significant to predict RP. However, it loses its significance when clinically important RP was considered. This effect might be further evaluated by largerscale studies.

In our findings, the patient characteristics were not found to be correlated with RP, which is a similar finding with the literature.[11] There has been a controversy on the association between age and RP [10]. A study reported that age $\geq 70$ years was an independent factor for RP.[12] However, in some other studies, age $>60$ years was found to be associated with an increased risk of RP. $[5,13]$ On the other hand, a large-scale study with 576 patients did not find any difference in the incidence of RP between patients whose age is over or under 60 years, which is similar to our results.

In our study, there was no any association between gender and RP. The effect of gender on lung function after thoracic RT is also conflicting in the literature. [10] Though some studies stated that women had higher risk for RP, a meta-analysis reported no association between gender and RP.[14]

The mean baseline PFT values and incidence of $\mathrm{RP}$ of our cohort are in accordance with the literature. $[5,11]$ The literature has conflicting reports considering the correlation between baseline PFT and risk of $\mathrm{RP}$; some studies reported lower incidence of RP in patients with better PFT, whereas some other studies found no correlation. [5,15-18] Even the study by Wang et al.[11] found that patients with RP ( $\geq$ grade 2 ) have marginally higher FVC than patients without RP.

In contrast to many studies, we did not find the baseline FEV1 as a prognostic factor for survival. $[4,11,19]$ This might be due to the relatively low number of our patient cohort.

\section{Limitations of the Study}

Our study has several limitations. The retrospective nature of the study that makes it subject to multiple biases and relatively small number of patients are the major limitations. In addition, data on COLD and smoking history are lacking. Moreover, loss of patients during follow-up to have PFT is another limitation. The quality of life (QoL) data is also missing.

On the other hand, homogenous study population, composed of only stage III patients treated with the same concurrent RCT protocol over a relatively short period, assessment of RP retrospectively by reviewing the radiological findings during follow-up by radiation oncologist and chest physician together one by one in each case, and relatively longer follow-up time could be suggested as the strengths of our study. In addition, we repeated the analysis by excluding relapsing patients; by this way, we were able to exclude the effect of salvage therapies and confounding factors related to recurrence that might have negative impact on PFTs.

\section{Conclusion}

In spite of the underpowered nature of our study, our findings may show attention to prominent and persistent decrease in PFT after RCT. However, the clinical outcome of this finding has to be evaluated by the QoL data. Further prospective studies with larger scales are needed to verify the predictive value of baseline DLCO on the development of RP. The regional functional mapping and the evaluation of functional dosimetric parameters during RT planning by using ventilation/ perfusion single positron emission computerized to- 
mography might provide additional data to predict RP risk better than anatomical dosimetric data.

Conflict of Interest: None declared.

Peer-review: Externally peer-reviewed.

Ethics Committee Approval: This study was conducted in accordance with local ethical rules.

Financial Support: None declared.

Authorship contributions: Concept - E.K.K., U.Y.; Design - E.K.K., U.Y.; Supervision - U.Y.; Materials - U.Y.; Data collection \&/or processing - E.K.K.; Analysis and/or interpretation - E.K.K.; Literature search - E.K.K.; Writing - E.K.K., U.Y.; Critical review - U.Y.

\section{References}

1. Sause W, Kolesar P, Taylor S IV, Johnson D, Livingston $\mathrm{R}$, Komaki R, et al. Final results of phase III trial in regionally advanced unresectable non-small cell lung cancer: Radiation Therapy Oncology Group, Eastern Cooperative Oncology Group, and Southwest Oncology Group. Chest 2000;117(2):358-64.

2. Cox JD. Are the results of RTOG 0617 mysterious? Int J Radiat Oncol Biol Phys 2012;82(3):1042-4.

3. Cerfolio RJ, Talati A, Bryant AS. Changes in pulmonary function tests after neoadjuvant therapy predict postoperative complications. Ann Thorac Surg 2009;88(3):930-5; discussion 935-6.

4. Semrau S, Klautke G, Fietkau R. Baseline cardiopulmonary function as an independent prognostic factor for survival of inoperable non-small-cell lung cancer after concurrent chemoradiotherapy: a single-center analysis of 161 cases. Int J Radiat Oncol Biol Phys 2011;79(1):96-104.

5. Torre-Bouscoulet L, Muñoz-Montaño WR, MartínezBriseño D, Lozano-Ruiz FJ, Fernández-Plata R, BeckMagaña JA, et al. Abnormal pulmonary function tests predict the development of radiation-induced pneumonitis in advanced non-small cell lung Cancer. Respir Res 2018;19(1):72.

6. Cox JD, Stetz J, Pajak TF. Toxicity criteria of the Radiation Therapy Oncology Group (RTOG) and the European Organization for Research and Treatment of Cancer (EORTC). Int J Radiat Oncol Biol Phys 1995;31(5):1341-6.

7. Borst GR, De Jaeger K, Belderbos JS, Burgers SA, Lebesque JV. Pulmonary function changes after radiotherapy in non-small-cell lung cancer patients with long-term disease-free survival. Int J Radiat Oncol Biol Phys 2005;62(3):639-44.
8. Gopal R, Starkschall G, Tucker SL, Cox JD, Liao Z, Hanus $M$, et al. Effects of radiotherapy and chemotherapy on lung function in patients with non-small-cell lung cancer. Int J Radiat Oncol Biol Phys 2003;56(1):114-20.

9. Takeda S, Funakoshi Y, Kadota Y, Koma M, Maeda H, Kawamura S, et al. Fall in diffusing capacity associated with induction therapy for lung cancer: a predictor of postoperative complication? Ann Thorac Surg 2006;82(1):232-6.

10. Kong FM, Wang S. Nondosimetric risk factors for radiation-induced lung toxicity. Semin Radiat Oncol 2015;25(2):100-9.

11. Wang J, Cao J, Yuan S, Ji W, Arenberg D, Dai J, et al. Poor baseline pulmonary function may not increase the risk of radiation-induced lung toxicity. Int J Radiat Oncol Biol Phys 2013;85(3):798-804.

12. Dang J, Li G, Zang S, Zhang S, Yao L. Risk and predictors for early radiation pneumonitis in patients with stage III non-small cell lung cancer treated with concurrent or sequential chemoradiotherapy. Radiat Oncol 2014;9:172.

13. Palma DA, Senan S, Tsujino K, Barriger RB, Rengan $\mathrm{R}$, Moreno $\mathrm{M}$, et al. Predicting radiation pneumonitis after chemoradiation therapy for lung cancer: an international individual patient data meta-analysis. Int $\mathrm{J}$ Radiat Oncol Biol Phys 2013;85(2):444-50.

14. Vogelius IR, Bentzen SM. A literature-based metaanalysis of clinical risk factors for development of radiation induced pneumonitis. Acta Oncol 2012;51(8):975-83.

15. Robnett TJ, Machtay M, Vines EF, McKenna MG, Algazy KM, McKenna WG. Factors predicting severe radiation pneumonitis in patients receiving definitive chemoradiation for lung cancer. Int J Radiat Oncol Biol Phys 2000;48(1):89-94.

16. Dehing-Oberije C, De Ruysscher D, van Baardwijk A, Yu S, Rao B, Lambin P. The importance of patient characteristics for the prediction of radiation-induced lung toxicity. Radiother Oncol 2009;91(3):421-6.

17. Lind PA, Marks LB, Jamieson TA, Carter DL, Vredenburgh JJ, Folz RJ, et al. Predictors for pneumonitis during locoregional radiotherapy in high-risk patients with breast carcinoma treated with high-dose chemotherapy and stem-cell rescue. Cancer 2002;94(11):2821-9.

18. Chen S, Zhou S, Zhang J, Yin FF, Marks LB, Das SK. A neural network model to predict lung radiation-induced pneumonitis. Med Phys 2007;34(9):3420-7.

19. Kim H, Lussier YA, Noh OK, Li H, Oh YT, Heo J. Prognostic implication of pulmonary function at the beginning of postoperative radiotherapy in non-small cell lung cancer. Radiother Oncol 2014;113(3):374-8. 